\title{
ADOPTION OF INSECT-EATING THROUGH PACKAGING DESIGN
}

\author{
S.-M. Kauppi ${ }^{1, \bigotimes}$ and S. van der Schaar ${ }^{2}$ \\ ${ }^{1}$ Norwegian University of Science and Technology, Norway, ${ }^{2}$ Wageningen University \& Research, \\ The Netherlands \\ $\varangle$ saara.m.kauppi@ntnu.no
}

\begin{abstract}
Edible insects have been introduced as a novel protein source. Although the rationales for insecteating highlight the urgency of changing diets into more sustainable solutions, there is still a need for better understanding how packaging design is related to adoption of insects. Much consumer research has been conducted to understand the acceptance of insects, but packaging design connected to practices has been given less focus. This article looks at packaging as a medium for stimulating adoption and links an empirical study on analogies for packaging design to practices of eating insects.
\end{abstract}

Keywords: communication, sustainability, packaging, edible insects, consumer acceptance

\section{Introduction}

One proposed solution for the global population growth and anthropogenic climate change is the use of insects as human food in the West ${ }^{1}$. The recent research has proposed insects to be a sustainable animal protein source, mainly due to environmental benefits since insects require considerably less feed (Collavo et al., 2005), water (Miglietta et al., 2015) and rearing space (Van Huis et al., 2013) and emit fewer greenhouse gases (Oonincx et al., 2010) than other animal-based protein sources on land. From the efficiency point of view in farming, insects gain their full body weight within a few months of time and can then be used for food (van Huis et al., 2013). Also nutritional benefits of insects are well grounded, they are relatively low in fat, high in protein and contain micronutrients valuable for human nutrition (Van Huis et al., 2013).

Consumer research has attempted to identify possible early adopters in the West by understanding what motivates people to eat insects. Much research has proposed strategies to overcome barriers to eating insects, but majority of people in the West are still not ready to add insects to their daily diets. Often studies that focus on 'consumer acceptance' underemphasise the social and contextual nature of food consumption ${ }^{2}$ (House, 2016). Therefore, looking closely at the eating behaviour of 'early adopters' could be viewed as the entry point of understanding how novel foods enter new locations and diets (House, 2018). Design interventions, especially packaging design, can be targeted to the prospective consumer groups for example to early adopters, which can consequently aid the promotion of novel food products in the supermarket (Kauppi et al., 2019). The combination of these

\footnotetext{
${ }^{1}$ In this article the term West covers geographic entities of Europe, North America and Australia-New Zealand, where entomophagy - insect eating - practice have been less dominant in recent years (van Huis et al., 2013).

${ }^{2}$ Consumption in this article refers to the act of purchasing and eating a product.
} 
two approaches provides a starting point for understanding practices of eating insects through the use of design interventions. The purpose of this paper is to investigate packaging design as a medium for introducing the practice of eating insects, linking a study on analogies of mealworms to modes of eating insects. First the article introduces the consumer research on insect-eating, then it presents packaging design as a medium for promotion and how it can be linked to consumption. Lastly a study on analogies is introduced to understand how packaging design can be used as a medium for novel foods such as insects.

\section{Adoption of insects}

\subsection{Modes of eating insects}

The modes of eating insects by House (2018b) will work as a theoretical background for linking modes of eating insects with insect-based food products. Looking at consumers' eating practices helps to understand the practice-based context when introducing packaging design for mealworms. House (2018b) introduces mundane and elaborate modes of eating by studying the consumption of Insecta burger. The Mundane mode of eating describes the ordinary way of consumption that links everyday practices of preparing food to a bundle of routines and continuity, which are occasionally broken by more elaborate mode of eating. The elaborate mode of eating is described as an exception from the ordinary, often being social and having negotiations on food and possibly taking more time than the mundane mode. As an addition to House (2018b) study, this paper will include that consumption modes are not only dependent on social, practical and contextual conditions, but also the food product itself. The consumption of Insecta burger in the study was linked to mundane modes of practices as the product was a readymade burger, quick and easy to prepare. Perhaps whole insects that are introduced in our study could be linked to more elaborate modes of consumption, as whole insects often require learning about preparation methods and can then include social aspects such as insect tastings or social cooking. Furthermore, Looy and Wood (2006) noted that Bug Banquets increase of people trying insects as a possible result of peer pressure within those gatherings.

\subsection{Packaging design and consumption}

The term packaging design in this article is mainly used to discuss the use of graphic design linked to promotion of convenience products. Packaging is described to be 'the silent salesman' Pilditch (1961) that creates an identity to the product and is tightly interconnected with it. The design helps the product stand out in the supermarket, promote a desirable price range, advertise the brand and inform the consumer visually and verbally about the product. Furthermore, consumers make quality judgements based on a product's image, information and appearance (Grunert, 2005; Zeithaml, 1988). In addition consumers feel time pressure in the supermarkets, therefore consumers make purchase decisions based on imagery information and they spend less time reading the product descriptions (Baker et al., 2016). Most of the buying decisions for daily groceries are made in-store, of which $90 \%$ of the products are purchased while consumers have only looked at the front of the packaging (Clement, 2007). This shows that consumers are most influenced by the product packaging when they make their buying decisions, which stresses the key role of packaging in the sales of consumer (food) products (Ampuero, 2006; Rundh, 2005, 2009). Important elements that influence the appearance of a packaging are shape, texts, size, colour, texture and graphics (Ampuero, 2006; Rundh, 2005, 2009). For example, a colour can be the trademark of a brand and therefore create meaning, or it can create expectations of certain flavours (Madden et al., 2000; Piqueras-Fiszman and Spence, 2011) and graphics can make, due their high noticeability, the difference between noticing or missing the product (Silayoi and Speece, 2007). Next to that, graphics are especially important in low involvement buying decisions, such as groceries (Silayoi and Speece, 2007). Moreover, the combination of these elements provides a multisensory perception of the packaging, in which the overall effect of the combined elements can lead to a deeper connection between the consumer and the product (Joutsela, 2010; Orth and Malkewitz, 2008).This is especially important in novel, unfamiliar products, as people have no connection to these products yet (Heiskanen et al., 2007). New ideas can be communicated via visual 
cues and storytelling on the packaging (Joutsela, 2010), or instance, the idea of eating insects can be communicated via the right packaging cues.

Looking at the purchase experience from consumers' perspective, the product goes through an evaluation process in the supermarket to its price, ingredients, nutritional benefits, alleged taste, size, brand, expire date and 'fitting with the current eating practices'. When the choice has been made, the product selected and the consumer approaches the cashier, another visual evaluation occurs in the supermarket, 'Is this worth buying?'. Similarly, just before tasting the new product for the first time another round of evaluations occurs. This may contain observing the product and the packaging carefully. Finally opening the product follows sensory testing, such as touching, smelling and tasting. Consumers may seek for further information about the ingredients, the nutritional facts, cooking instructions, production information, the expire date and additional promotional information. When the product has been tested (including tasting, chewing and swallowing), the evaluation process from sensory to rationale begins. If the product tastes good and the consumer finds the product valuable enough for repurchase, the design reminds the consumers of the good sensory experience. As a good sensory experience may increase consumption intentions (Tan et al., 2017), design has a role for emphasising that experience. However, if the consumption experience is unpleasant, the packaging can be evaluated even more carefully looking for justification for the negative experience. As negative tasting experiences will very likely have a negative impact on introducing insects as food (Tan et al., 2017), consumers may label the design with the bad experience. It can be concluded that packaging gives an identity for a product that will be either remembered or discarded in the future, depending on the multiple factors connected with the consumer experience with the product.

\section{Consumer study on insect packaging}

\subsection{Background}

The study was conducted at Wageningen University and Research (WUR) in 2018-2019 to understand whether similarity-based 'taste and texture like seeds' and relational 'prepare like falafel' analogies (comparisons of products that are alike (Gregan-Paxton and Moreau, 2003) on the packaging of whole freeze-dried mealworms would increase the acceptance of the product. The study was a collaboration and part of a research exchange between Norwegian University of Science and Technology NTNU and WUR during October 2018 and June 2019.

\subsection{The study description}

The consumer study contained two parts. Firstly, a focus group discussion (henceforth, 'discussions') to find desirable analogies for mealworms, as consumers often create analogies 'comparisons' of products that are new to them (Gregan-Paxton and Moreau, 2003). Secondly, an international survey to find out which analogies work the best for Western consumers. For the discussions, 12 participants were recruited from the Netherlands via the social media site Facebook, and via researchers' personal contacts. The groups were divided into six experienced and six inexperienced consumers with eating of mealworms. The intention was that the groups could share and discuss their ideas on the topic. The discussions then resulted in analogies, which were used on the packaging for the survey. This order of methods ensured that the used analogies on the product packaging were supported by the consumers that have been consuming mealworms. The group of inexperienced consumers on the other hand, gained further understanding of the first impressions of eating insects without actually consuming them. The literature suggests two types of analogies for introducing foreign food. Similarity-based analogies are based on shared physical features (e.g. taste or texture) (Holyoak and Koh, 1987) and relational analogies are based on shared functionality (e.g. same function in a meal) (Gregan-Paxton and Moreau, 2003; Holyoak and Koh, 1987). The chosen analogies for similarity-based analogy and relational analogy were obtained from the discussions and were visualised on a product packaging for a mealworm product containing dried mealworms. This was done with the use of images, graphics, colours, texts and typography. These packages were designed using Adobe InDesign. To make the products look as realistic as possible, packaging 
designs of existing meat substitutes from the Dutch supermarket chain Jumbo were examined for inspiration.

\subsection{First part: results from the focus group discussions}

The discussions resulted in ideas for further packaging design. The ideas were then rated, and the most preferred ideas were placed on the packaging. The chosen relational analogy 'how to prepare mealworms' was falafel in the discussion group of inexperienced consumers, and salad in the experienced group. Interestingly, most of the participants who were inexperienced with eating mealworms did not like the idea of mealworms in a salad, as they felt it was a disgusting combination. Therefore, falafel was chosen as the relational analogy by the groups. The notable difference between these two discussions was that inexperienced consumers were much more careful about the combinations of insects and other known food, whereas the experienced group was more experimental about combining insects with other food.

Table 1. Analogies for mealworms by both focus groups; The similarity-based analogy refers to comparisons of texture and taste; Relational analogy refers how the food can be used

Analogies for mealworms by the inexperienced group in insect-eating

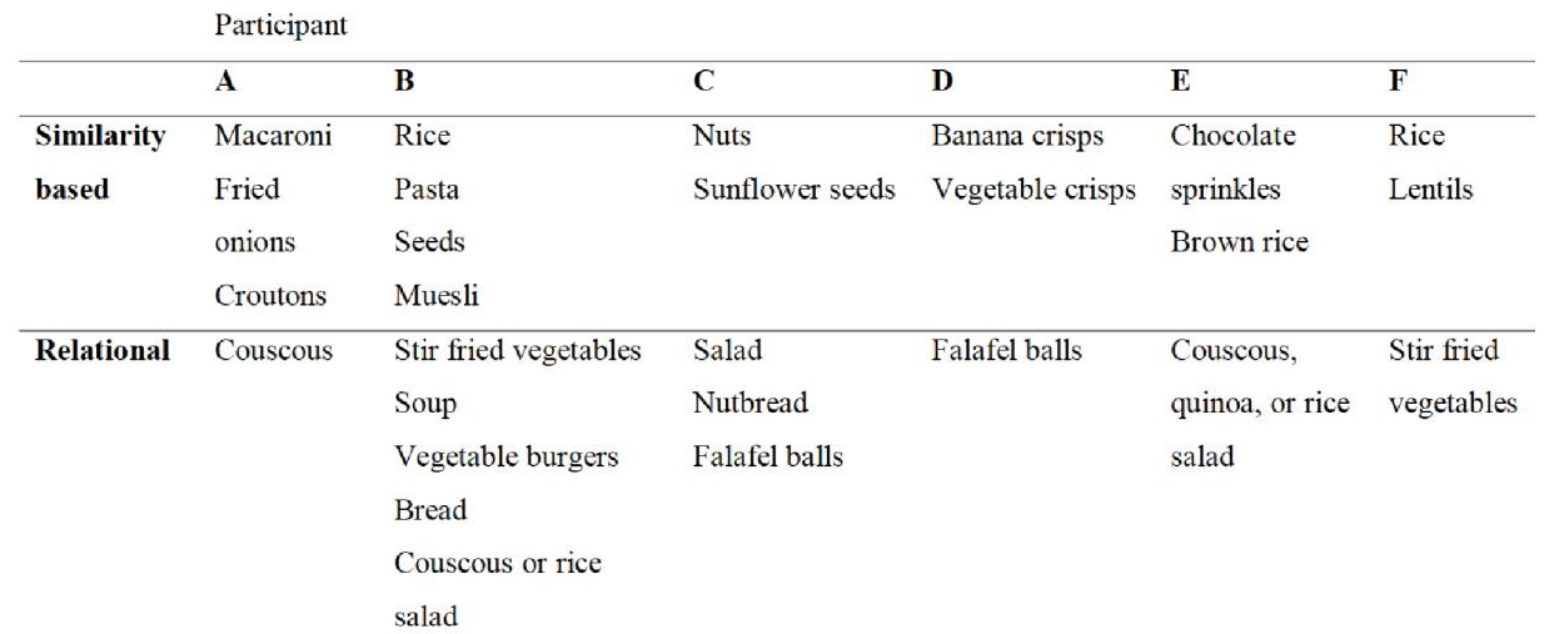

Analogies for mealworms by the experienced group in insect-eating

Participant

\begin{tabular}{lllllll}
\hline & A & B & C & D & E & F \\
\hline $\begin{array}{l}\text { Similarity } \\
\text { based }\end{array}$ & Walnuts & Seeds & Seeds & Popcorn & Nut-like taste & Mini pasta \\
& & $\begin{array}{l}\text { Crispiness similar } \\
\text { to } M \& M s\end{array}$ & & Airy crisps & $\begin{array}{l}\text { Puffed peas } \\
\text { Nut-like taste }\end{array}$ \\
& & & & & \\
\hline Relational & Couscous or & Salad & Fried bacon & Croquette & Wok dish & Salad \\
& pasta salad & Noodle dish & Omelette & Frikandel & Oven dish & Alongside \\
& & & Stew & Pancakes & & potatoes and \\
& & & Meatballs & & & vegetables
\end{tabular}

Pasta Bolognese

\subsection{Second part: the packaging survey}

The design motives on the packages were based on the focus group discussions. This required a couple of compromise as the experienced and inexperienced groups were not unanimous on what should be placed on the packaging. For example, the inexperienced consumers did not like the idea of adding mealworms with salad, whereas the experienced consumers were suggesting salad as one 
of the appropriate ways to consume mealworms. Eventually, falafels were chosen as the relational analogy on the package as both groups had it on the top of their preference. Another compromise was needed for the name of the packaging, as neither 'mealworms' as a word nor showing the actual insects (mealworms are larvae from a beetle) were desired by both of the groups (see Table 2). However, both groups still wanted to stress the product authenticity, therefore the title of the product became 'Happy Worms' as an indirect reference to mealworms instead of a direct reference, also suggested by Baker et al. (2016). In addition, 'Happy worms' could be seen as a positive reinforcement for ethical perspectives on farming insects. Next to that, a small corner of transparency was added as both discussions agreed that it was desirable to see the actual content (see Table 2). The green colour palette of the design was preferred by the participants for referring to insects' environmental benefits and health benefits (Table 2). The overall aim of the design was to convey an idea of a healthy, fair and sustainable product for people who would be interested in such product.

Table 2. Packaging ideas by both focus groups

\section{Packaging ideas by the inexperienced group in insect-eating}

\begin{tabular}{ll} 
Desired & Not desired \\
\hline Information on protein content & Stress that the product is an insect \\
\hline $\begin{array}{l}\text { Analytics that show why you should eat } \\
\text { mealworms: their sustainability and healthiness }\end{array}$ & $\begin{array}{l}\text { Mealworms shown in a curvy shape, because } \\
\text { that resembles that they are alive }\end{array}$ \\
\hline Suggestions on what to do with the product & Real images of (living) mealworms \\
\hline Show the mealworms in a dish & Mealworm images all over the packaging \\
\hline Abstract image of mealworm & Stress that the product is a worm \\
\hline Attractive but peaceful colours, e.g. green & Communicate that the product is better than meat \\
\hline Similar looks to other meat substitute packages & Sober colours, e.g. grey \\
\hline Small piece of transparency & Target a specific group
\end{tabular}

\section{Packaging ideas by the experienced group in insect-eating}

\section{Desired}

Communicate the pros of eating mealworms

Attractive claims

Appeal to broad audience

Small piece of transparency

Make it look like the packaging of a similar product

Picture of a dish with visible mealworms

Drawing of a mealworm mascot

Rich, lively colours

Make clear what you can do with the product

\section{Undesired}

Emphasis on insect

The word "mealworm" in the title

\section{Close-up of mealworms}

Realistic pictures of mealworms

Colour of packaging not similar to colour of the mealworms

Make it look too alternative

Picture of the mealworm beetle

Target at a specific group

Picture of drawing of mealworm should not be in

the centre of the packaging 


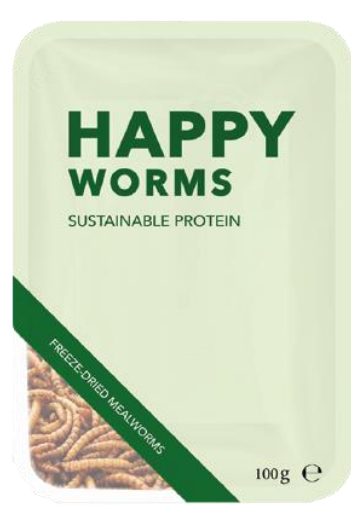

A) No analogy.

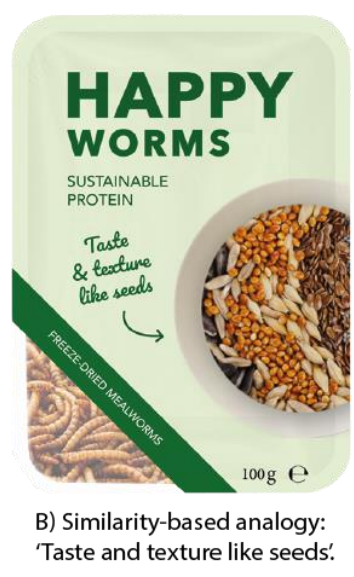

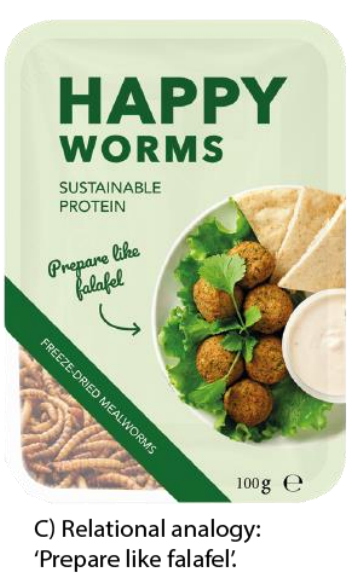

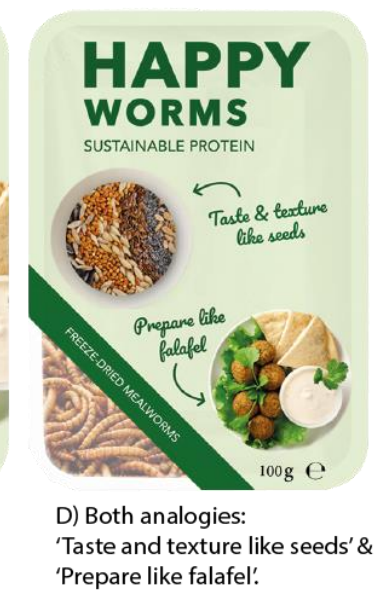

Figure 1. Packaging designs for survey, designs by the authors; Relational analogy $(C)$ and the packaging with both analogies (D) scored highest in the consumer test for acceptance of mealworms

\subsection{Description of the survey}

The survey was created with the program Qualtrics, and participants could fill in the survey on a computer or a mobile device online. Participants were given the four designs in a random order to make comparisons possible. The participants received questions regarding their preference of the product, food neophobia, sustainability, importance of product packaging and demographics (see Figure 2). The questions regarding the product, food neophobia and importance of product packaging had to be answered on a 5-points Likert scale (1 Strongly disagree, 2 Disagree, 3 Neither disagree nor agree, 4 Agree and 5 Strongly agree).

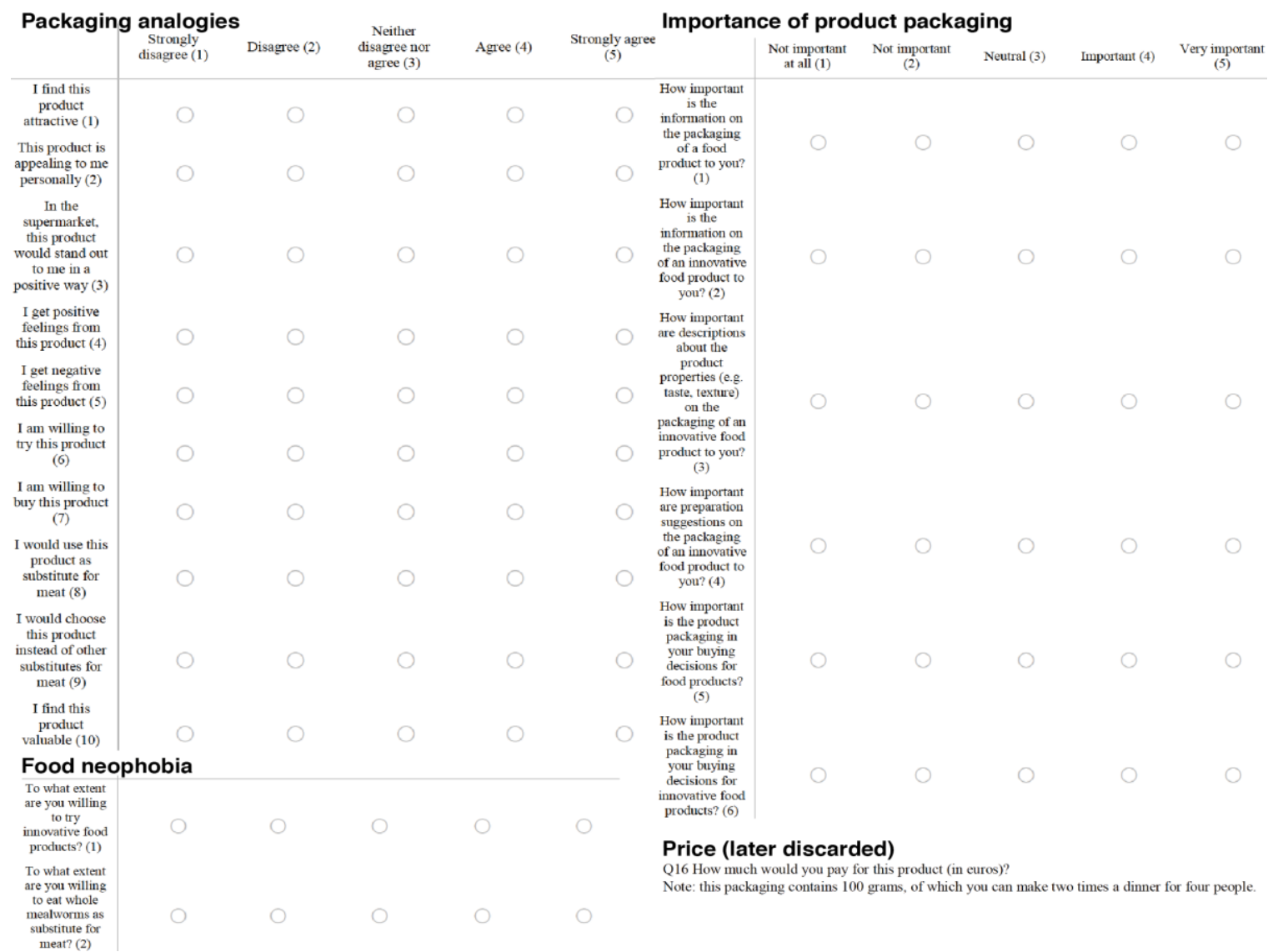

Figure 2. Examples of the survey questions on food neophobia, packaging analogies and importance of product packaging, and price that was later discarded 
The design without any analogies and visual triggers was used as the control condition. All questions were the same for each design, and thus repeated four times. Following the four designs, questions on the participant's food neophobia, sustainability, and importance of product packaging were asked. After demographic questions on age, gender, and nationality, the questionnaire ended with the option to comment on the topic or give suggestions.

\subsection{Analysis}

Results from the survey were analysed with use of the statistics program SPSS. It was checked whether reliable factors could be made from the data, then Cronbach's alpha was used to check the scale reliability. Three overarching factors acceptance, evoking negative feelings, and price were made to measure the consumer preference in variable ways. However, the price factor was later discarded, since the participants were from multiple countries having several currencies and economic situations. Variables were manually created for the three factors for each type of packaging to run the repeated measures with ANOVA analysis. This test was done to find the differences in consumer preference between the different packages. First, Q-Q plots were made of the new variables to assure for normality. The other assumptions were tested including the level of variables, independence of the scores, and sphericity. After testing whether the data met the assumptions, the ANOVA test, including pairwise comparisons, was used to compare means of the three factors between the different designs. Because there was only one group of respondents who tested all packages, the scores were independent. The last assumption of sphericity could not be met. For each construct, sphericity was significant 35 ( $\mathrm{p}<0.01)$, and thus violated. This meant that the values of the Greenhouse-Geisser test, with adjusted degrees of freedom, had to be used in the ANOVA test. Moreover, ANOVA significance factor was 0.01 . The results of the ANOVA test showed that the type of packaging had a significant influence on each construct. These results can be found in Table 3.

Table 3. Results of the ANOVA test for the influence of packaging type on each construct

\begin{tabular}{llll}
\hline Construct & Mean Square & F & Sig. \\
\hline Acceptance & 17.880 & 69.361 & $0.000^{*}$ \\
\hline Negative feelings & 7.184 & 10.863 & $0.000^{*}$ \\
\hline Price & 70.798 & 29.551 & $0.000^{*}$ \\
\hline
\end{tabular}

$$
* \mathrm{p}<0.01
$$

Similarly to the focus group discussions, the analysis of the survey was also carried out by splitting the data into two sets, the experienced and inexperienced consumers. One set contained the data of all inexperienced participants who had not consumed mealworms, and the second data set contained the data of all experienced participants with eating of mealworms.

\subsection{Results}

In total, the survey was completed by 115 people, from which 51 were male (44.3\%) and 64 were female (55.7\%). Age ranged from 16 to $81(\mathrm{M}=37.12 ; \mathrm{SD}=15.88)$. Participants were different Western nationalities: Dutch 69, Belgian 21, German 8, Finnish 4, Norwegian 3, British 3, Swedish 3, French 2, Spanish 1 and American 1. More than half of the participants were willing to eat insects in general, and 32 participants had experience with eating mealworms.

Participants rated the information on product packages of novel foods important. Similarly, information on product properties such as taste and texture, and preparation suggestions on the packaging of a novel food product were classified as highly important. All designs evoked negative feelings among the respondents, but by using analogies the acceptance rate got higher. The neutral packaging ( $1 \mathrm{~A})$ without 
any analogy and visual triggers was least preferred by all the respondents and even evoked negative feelings towards the product. The experienced consumers, preferred both analogies (1 D) over the others, but the difference was not big compared to the acceptance of relational analogy $(1 \mathrm{C})$. Among all participants there were no substantial differences in preference between the packages with the relational analogy $(1 \mathrm{C})$, and both analogies $(1 \mathrm{D})$, as both designs scored well. However, in the total scoring the packaging with the similarity-based analogy $(1 \mathrm{~B})$ was less preferred than the packages with relational analogy (1 C), and both analogies (1 D). The results can be found in Table 4.

Table 4. Mean values for the three different factors; The values for acceptance and negative feelings were given on a 5-points Likert scale

\begin{tabular}{|c|c|c|}
\hline & \multicolumn{2}{|c|}{ Mean (SD) for all participants $(\mathrm{n}=115)$} \\
\hline Type of packaging & Acceptance & Negative feelings \\
\hline Neutral & $2.2(0.85)$ & $3.2(1.16)$ \\
\hline Similarity based analogy & $2.8(0.95)$ & $2.8(1.09)$ \\
\hline Relational analogy & $3.0(0.95)$ & $2.7(1.03)$ \\
\hline \multirow[t]{2}{*}{ Both analogies } & $3.0(0.95)$ & $2.7(1.03)$ \\
\hline & \multicolumn{2}{|c|}{ Mean (SD) for all unexperienced participants $(n=83)$} \\
\hline Type of packaging & Acceptance & Negative feelings \\
\hline Neutral & $2.1(0.81)$ & $3.3(1.13)$ \\
\hline Similarity based analogy & $2.7(0.92)$ & $2.9(1.04)$ \\
\hline Relational analogy & $2.9(0.95)$ & $2.9(1.03)$ \\
\hline \multirow[t]{2}{*}{ Both analogies } & $2.8(0.95)$ & $2.8(1.03)$ \\
\hline & \multicolumn{2}{|c|}{ Mean (SD) for all experienced participants $(n=32)$} \\
\hline Type of packaging & Acceptance & Negative feelings \\
\hline Neutral & $2.5(0.91)$ & $3.0(1.20)$ \\
\hline Similarity based analogy & $3.0(0.98)$ & $2.7(1.23)$ \\
\hline Relational analogy & $3.3(0.90)$ & $2.4(0.94)$ \\
\hline Both analogies & $3.3(0.91)$ & $2.5(1.02)$ \\
\hline
\end{tabular}

\section{Discussion}

The study investigated analogies for acceptance of whole mealworms as meat substitute. Four different designs were made based on focus group discussions. The designs with analogies were preferred more than the control design without any analogies on the packaging. The relational analogy (Figure $1 \mathrm{C}$ ) 'prepare like falafel' and the design with both analogies (Figure $1 \mathrm{D}$ ) 'prepare like falafel' and 'taste and texture like seeds' were the most preferred designs in the survey. There was a minor difference between the experienced and inexperienced consumers with insect-eating, as the experienced consumers preferred both analogies over the relational analogy. The inexperienced consumers preferred the relational analogy for mealworms. Similarity-based analogy 'taste and texture like seeds' (Figure $1 \mathrm{~B}$ ) was preferred more than no-analogy, but less than relational analogy or the design with both analogies. An underlying reason why 'prepare like falafel' was preferred over 'taste and texture like seeds' could be that falafel gave an idea of a proper dish, compared to seeds that is an ingredient, usually used for garnishing salads and used less as a meat substitute. Also, an image of a prepared dish offers more information about the food and gives a concrete suggestion what to do with the product. For these reasons it could be seen as more attractive option by the consumers. 
Comparing experienced and inexperienced consumers, the inexperienced consumers are more cautious of combining insects with other food. This became apparent when inexperienced consumers did not accept mealworms with salad in the focus group discussions. The notion that inexperienced consumers are more cautious is a practical finding that could be taken into account when promoting insects. Perhaps emphasising one culturally known dish for insect-eating could work better than introducing the variety of insect-based foods for the wider audience. Having a lot of variety on insect-based foods can make the consumers confused about the purpose of eating insects especially if the food conflicts the initial idea of reducing meat consumption, especially when insects are introduced in foods that are originally plant-based without animal meat.

The results of the packaging test relate to practices and modes of eating insects. The results verify that practices are an important factor to include in the promotion of insects. The relational analogy 'prepare like falafel' highlighted the importance of preparation of insects that is a clear message how to use the product. Moreover, product packaging can be utilised as a promoter of practices for targeting the longterm adoption of insects. Analogies are often used for introducing novel food and combining analogies with practices of known food could be the an impactful method for marketing insects. In the end, the product usage and the design of it determine how well it can be included into existing practices.

The empirical study also reminds how design is a process with multiple stakeholders. Co-designing with consumers is a dialogue through which the claims and the visual motives are suggested. Interestingly, designing with consumers often requires compromises, since consumers are not a homogeneous group of similar opinions. Co-designing, however, with consumers is a good opportunity to gain better results that could make consumers more engaged with the end product. Although the consequence is that it also reduces the authority of a designer as a decision-maker in the process.

Lastly, the promoters of edible insects can take an advice from this study to consider practices and analogies as part of practical suggestions when designing and promoting insect-eating for a wider audience. However, a more thorough study on practices of insect-eating linked to the variety of insectbased foods is suggested, since the product guides the eating practices as well as the existing practices will determine if the product is ultimately accepted.

\section{Conclusion}

Designing a product packaging for novel food such as edible insects is an important process for gaining consumers' trust. This article suggests the use of analogies on the product packaging to help increasing consumer acceptance of whole mealworms. The results conclude that especially relational analogies 'how insects can be used' could be a useful strategy for introducing novel food for inexperienced consumers of eating mealworms. The experienced consumers on insect-eating on the other hand preferred to have both analogies, the relational 'usage comparison' and similarity-based analogy 'taste and texture comparison' on the packaging. Consumption modes and eating practices are not only dependent on social, practical and contextual conditions, but also the food product itself. Therefore, understanding the use of the product and practices is important for long-term adoption of novel foods. Finally, packaging can be used as a medium for obtaining knowledge about the product and the use of it. This can be done together with the prospective consumers for gaining the optimal analogies and product claims designed on the packaging.

\section{References}

Ampuero, O. (2006), “Consumer perceptions of product packaging”, Journal of Consumer Marketing, Vol. 23 No. 2, pp. 100-112. https://dx.doi.org/10.1108/07363760610655032

Baker, M.A., Shin, J.T. and Kim, Y.W. (2016), "An Exploration and Investigation of Edible Insect Consumption: The Impacts of Image and Description on Risk Perceptions and Purchase Intent", Psychology \& Marketing, Vol. 33 No. 2, pp. 94-112.

Clement, J. (2007), "Visual influence on in-store buying decisions: an eye-track experiment on the visual influence of packaging design", Journal of Marketing Management, Vol. 23 No. 9-10, pp. 917-928. https://dx.doi.org/10.1362/026725707X250395

Collavo, A. et al. (2005), "House cricket small-scale farming", In M.G. Paoletti, ed., Ecological implications of minilivestock: potential of insects, rodents, frogs and snails, pp. 519-544 
Gregan-Paxton, J. and Moreau, P. (2003), "How Do Consumers Transfer Existing Knowledge? A Comparison of Analogy and Categorization Effects", Journal of Consumer Psychology, Vol. 13 No. 4, pp. 422-430.

Grunert, K.G. (2005), "Food quality and safety: consumer perception and demand", European Review of Agricultural Economics, Vol. 32 No. 3, pp. 369-391. https://dx.doi.org/10.1093/eurrag/jbi011

Heiskanen, E. et al. (2007), "User Involvement in radical innovation: are consumers conservative?", European Journal of Innovation Management, Vol. 10 No. 4, pp. 489-509.

Holyoak, K.J. and Koh, K. (1987), "Surface and structural similarity in analogical transfer", Memory \& Cognition, Vol. 15 No. 4, pp. 332-340.

House, J. (2016), "Consumer acceptance of insect-based foods in the Netherlands: Academic and commercial implications", Appetite, Vol. 107, pp. 47-58.

House, J. (2018a), "Insects as food in the Netherlands: Production networks and the geographies of edibility", Geoforum, Vol. 94, pp. 82-93.

House, J. (2018b), "Modes of Eating and Phased Routinisation: Insect-Based Food Practices in the Netherlands", Sociology, Vol. 53 No. 3, pp. 451-467.

Joutsela, M. (2010). Multisensory Persuasion and Storytelling through Packaging Design: IAPRI International Association of Packaging Research Institutes.

Kauppi, S.-M., Pettersen, I.N. and Boks, C. (2019), "Consumer acceptance of edible insects and design interventions as adoption strategy", International Journal of Food Design, Vol. 4 No. 1, pp. 39-62.

Looy \& Wood (2006), “Attitudes toward invertebrates: are educational "bug banquets" effective?", The Journal of Environmental Education, Vol. 37 No. 2, pp. 37-48.

Madden, T.J. et al. (2000), "Managing Images in Different Cultures: A Cross-National Study of Color Meanings and Preferences", Journal of International Marketing, Vol. 8 No. 4, pp. 90-107. https://dx.doi.org/ 10.1509/jimk.8.4.90.19795

Miglietta, P.P. et al. (2015), "Mealworms for Food: A Water Footprint Perspective”, Water, Vol. 7 No. 11, pp. 6190-6203.

Oonincx, D.G. et al. (2010), “An exploration on greenhouse gas and ammonia production by insect species suitable for animal or human consumption", PLoS One, Vol. 5 No. 12, pp. e14445.

Orth, U.R. and Malkewitz, K. (2008), "Holistic Package Design and Consumer Brand Impressions", Journal of Marketing, Vol. 72 No. 3, pp. 64-81. https://dx.doi.org/10.1509/jmkg.72.3.064

Pilditch, J. (1961), The Silent Salesman: How to Develop Packaging that Sells, Business Publications.

Piqueras-Fiszman, B. and Spence, C. (2011), "Crossmodal correspondences in product packaging. Assessing color-flavor correspondences for potato chips (crisps)", Appetite, Vol. 57 No. 3, pp. 753-757.

Rundh, B. (2005), "The multi-faceted dimension of packaging: Marketing logistic or marketing tool?", British Food Journal, Vol. 107 No. 9, pp. 670-684. https://dx.doi.org/10.1108/00070700510615053

Rundh, B. (2009), "Packaging design: creating competitive advantage with product packaging", British Food Journal, Vol. 111 No. 9, pp. 988-1002. https://dx.doi.org/10.1108/00070700910992880

Silayoi, P. and Speece, M. (2007), "The importance of packaging attributes: A conjoint analysis approach", European Journal of Marketing, Vol. 41 No. 11-12, pp. 1495-1517. https://dx.doi.org/10.1108/ 03090560710821279

Tan, H.S.G., Verbaan, Y.T. and Stieger, M. (2017), "How will better products improve the sensory-liking and willingness to buy insect-based foods?", Food Research International, Vol. 92, pp. 95-105.

Van Huis, A. et al. (2013) "Edible insects: Future prospects for food and feed security", FAO Forestry Paper 171.

Zeithaml, V. (1988), “Consumer Perceptions of Price, Quality and Value: A Means-End Model and Synthesis of Evidence”, Journal of Marketing, Vol. 52, pp. 2-22. https://dx.doi.org/10.1177/002224298805200302 